\title{
Does Reformational philosophy have an answer to the many guises of pluralism?'
}

\author{
M. Elaine Botha \\ Department of Philosophy \\ Potchefstroom University for CHE \\ POTCHEFSTROOM
}

\begin{abstract}
Does Reformational philosophy have an answer to the many guises of pluralism?

Both the transformation of society and the inner reformation of the sciences require and are dependent upon global views of reality, society, man, nature and truth and implicitly harbour views of order. Moreover, Reformational philosophy as a transcendentalist project argues that all theoretical positions implicitly or explicitly harbour such global views. Dooyeweerd's philosophy, rooted in the 'metanarrative' of Christianity provides significant distinctions which make it possible to contextualize many of the issues raised in post-modernism. It is this type of global view that arouses the suspicion of postmodernists who have a strong suspicion about meta-narratives of any kind and especially notions of totality and universality.

In this paper it is argued that Reformational philosophy's emphasis on the diversity and coherence of the creational order and the diversity transcending fullness of meaning given in Jesus Christ provide significant barriers to counteract the phenomenon of 'wild pluralism' so characteristic of post-modernism's emphasis on pluralism in cultures and scientific theorizing.
\end{abstract}

1 This article is a revised version of a response to a paper by Sander Griffioen read at the Fifth International Symposium of the Association for Calvinist Philosophy, 2226 August 1994, Hoeven, the Netherlands. 


\section{Pluralism and communication in Reformational philosophy}

Dooyeweerd's transcendental critique of theoretical thought has a missionary and apologetic dimension which aims at making discussion between opposing philosophical schools of thought possible, convincing the discussing partners that all philosophical positions are bound to supratheoretical presuppositions which are intrinsically religious in nature. This attempt to advance discussion and communication amidst a plurality of positions is one ideal which Dooyeweerd's philosophy shares with many thinkers who emphasize the need for a 'conversation of mankind', dialogue, communication and the cultivation of community life. Dooyeweerd's proposed method and ultimate aims to achieve communication differ quite radically from the majority of projects proposed by post-modernist thinkers. His proposal to recognize the law order for reality as common denominator and basis for discussion would be rejected as essentialist in intent by most post-modern thinkers. On the other hand, Dooyeweerd, like post-modernist reasoning, has a fundamental appreciation of diversity and differentiation, perspectives, plurality, if you will. Yet, this emphasis too, differs quite fundamentally from postmodernist emphases on pluralism. The question posed by these superficial resemblances and fundamental differences is whether Dooyeweerd's transcendental critique can actually provide a bridge for communication between competing schools of thought and whether the understanding of plurality intrinsic to his notion of the coherence of diversity of reality, can overcome the relativistic effects so prevalent in what Bernstein (1987) calls "wild pluralism". It is with Reformational philosophy's possible response to the latter problem that I intend to deal in this paper.

I would like to argue that two central notions of Dooyeweerd's social philosophy provide significant points of departure to counteract the relativism and fragmentation so characteristic of post-modernism with its emphasis on pluralism. Recognition of the creational law order which conditions the world we live in, sets limits to the relativistic consequences of 'wild pluralism'. The diversity transcending notion of the fullness of meaning and the coherence of diversity on the other hand relativizes the absolute claims of pluralism. Dooyeweerd's transcendental critique provides us with a crucial Biblically conditioned insight that all possible diversity, albeit of reality, culture or scientific theories, are relativized by their relationship to the central point of reference of all of reality, human 
existence, human society and human knowledge - the fullness of meaning, Jesus Christ who has reconciled all things to God.

What characterizes Dooyeweerd's philosophy is its practically all encompassing scope. Departing from an epistemological problem he developed the contours of an extensive anthropology, philosophy of society, ecclesiology and ontology - a philosophical 'grand narrative' based on the assumption that in its attempt to identify the ontic structures conditioning our knowledge of reality, it would inter alia provide the basis for communication between competing philosophical schools. ${ }^{2}$ From his point of view both the transformation of society and the inner reformation of the sciences require and are dependent upon global views of reality, society, man and nature and truth - transcendental ground ideas. Moreover, Reformational philosophy as transcendentalist project, argues that all theoretical positions implicitly or explicitly harbour such global views. Dooyeweerd's transcendental critique of society and theories of society are not unproblematic. In Dooyeweerd's philosophy at least four possible notions of totality are found of which the transcendental idea of the meaning totality provides a diversity transcending point of reference (cf. Dooyeweerd, 1957:424-425). Yet, this notion harbours a certain ambiguity. The idea of the fullness of meaning, often translated as the totality of meaning, most probably ought to have been translated as the fullness, unity or the concentration of meaning. 'Totality' in the fourth sense of the term, appears open to at least the following renderings when read in conjunction with the definition of the task of philosophical sociology ${ }^{4}$ :

* Philosophical sociology provides a view of totality, i.e. a perspective on the whole of all societal relationships (in this sense there would

2 The problems related to the so-called 'pretence' of the transcendental critique is not argued here. Suffice it, at this stage, to refer only to the well-known discussion in Reformational circles pertaining to the problems raised by the so-called 'pretence' of the transcendental criticism proposed by Dooyeweerd (Van Riessen, 1970; Dooyeweerd, 1941).

3 Theodore Plantinga has strong reservations concerning the applicability of terms such as view and/or perspective to the Christian approach (cf. Plantinga, 1991).

4 The ambiguity of Dooyeweerd's conception of the 'social' and the various possible interpretations of his formulation of the field of study of Sociology as a discipline ought also to be taken into account here (cf. Botha, 1971). 
be an indication that Dooyeweerd seems to work with a notion of society as a temporal whole) (cf. Botha, 1971).

* Alternatively, philosophical sociology requires an Archimedean point which transcends the diversity of societal structures and in this sense the philosopher needs to find a standpoint within the totality of meaning in order to facilitate a 'correct' view of all societal institutions and their relationships. Such a position would prevent any form of totalitarianism or reductionism Dooyeweerd's philosophy argues, but of course constitutes some form of preconditionalism (Wolterstorff, 1984).

For the purposes of this paper these problematic aspects of his view of totality will not be dealt with. Suffice to say that sympathetically read, it is an attempt at philosophically formulating a pregnant Biblical insight that the coherent diversity of all reality is found in Christ the fullness of meaning. The question is, what consequences does this recognition have for post-modern views of pluralism.

\section{Pluralism the 'meta-narrative' of post-modernism}

Trying to come to terms with the factual state of affairs of "varieties of pluralism" (Bernstein, 1987) and the post-modernist emphasis on pluralism, one is knee deep in a whole plethora of possible and impossible forms of pluralism dealt with in related literature on this subject. Apart from multiculturalism and cultural pluralism one finds metaphysical pluralism, ontological pluralism, methodological pluralism, epistemological pluralism, theoretical pluralism, metaphorical pluralism, systematic pluralism and a host of other sorts and types of pluralism. The question arises whether the sophisticated and refined definitions and distinctions of structural and confessional pluralism that have been developed (Mouw \& Griffioen, 1993; McCarthy et al., 1981) in Reformational philosophy are adequate and sufficient to deal with fundamental problems of unity and diversity, constancy, change and solidarity and the spiritual antithesis which lie at the root of most of these forms of pluralism. Dooyeweerd's philosophy, rooted in the 'meta-narrative' of Christianity provides significant distinctions which make it possible to contextualize many of the issues, but the fundamental presupposition of his philosophy is a global view of reality and the recognition of a total view of society and a 'total' theoretical view underlying the scientific investigation of society. It is exactly this type of total view or global view that arouses the suspicion of 
M.E. Botha

post-modernists (Bernstein, 1987). Christian philosophers need not necessarily share this suspicion, but do need to give some account of the reasons why they do or do not feel comfortable with such a rejection of meta-narratives and global or universal views. Perhaps it is exactly the fact that post-modernism has developed its own meta-narrative: "There are no meta-narratives...!" which makes an uncritical acceptance of the postmodern stance untenable. This has been very succinctly argued by W.J.T. Mitchell who claims that pluralists are "closet dogmatists" who, especially in American intellectual life, have regarded the repression of dogmatism as a general acceptable strategy. Mitchell (1986:497) says:

Pluralism is a curious hybrid of dogmatic and ideological elements. In Pepper's version it is a dogmatic antidogmatism, a philosophy which pretends that it has no dogmas itself and which refuses to tolerate any other philosophy that admits to having a dogmatic basis, that is, a foundation in beliefs that exceed proper 'cognitive grounds'. Pluralism's first problem, then, is not that it has a dogmatic basis, but that it refuses to recognize that basis.

This basis Mitchell calls the ideological character of this refusal. Once this dogmatic trait in pluralism's emphasis on tolerance and relativism has been recognized, we need to have a closer look at the type of relativism which seems inevitably to accompany post-modem versions of pluralism.

\section{The potential anarchy of 'wild pluralism' and extreme relativism $^{6}$}

The phenomenon of pluralism and historicism (in the guise of relativism) is part and parcel of a broader trend which in many ways is characteristic of our daily lives (Bernstein, 1987:511). The consciousness of historical change is not only characteristic of contemporary culture - but also of our scientific and theoretical reflection about culture - to such and extent that Toulmin (1971) claims that the developments within philosophy of science are a litmus test for the basic changes taking place in wider culture. Bernstein (1987:516, 517) speaks of the almost chaotic babble of

5 I am indebted to Craig Bartholomew for this idea.

6 Bernstein (1987:522) introduces this term and points to the fact that Kuhn, Wittgenstein and Derrida are often cited as being in support of some wild pluralism. He disagrees with such a statement and argues that what emerges from Kuhn's, Wittgenstein's and Derrida's reflections on paradigms, language and translation is much closer to what he has characterized as being quintessential to the pragmatic understanding of pluralism. 
voes Reformational philosophy have an answer to the many guises of pluralism?

competing voices so characteristic of the range of cultural experience. At the same time there seems to be a significant preoccupation with community, solidarity and communication, especially at a local level. What makes these developments more acute is the fact that the pluralities have 'gone wild'. Bernstein (1987:522) argues that it has infected almost every aspect of human endeavour. He says: "This is a pluralism in which we are so enclosed in our own frameworks and our own points of view that we seem to be losing the civility, desire and even the ability to communicate and share with others."

Bernstein (1987:522) says we seem to be living through a time when there is "... a wild fluctuation between anxiety and celebration of radical differences". What is distinctive about the mood of our time, he (Bernstein 1987:522) says, "... is the odd and unstable mixture of a sense of fragmentation and of an interlocking system that develops according to its own logic and over which we do not seem to have any control". Central to these developments is the decentring of the Cartesian conception of the subject. To some extent Reformational philosophy has been as critical of the fundamental notions of modernism as post-modernism is today. But its critique of wild pluralism will be based not only on its modernist moorings, but more specifically on the lack of recognition of God's stable and reliable order for His creation. The critical question is what type of 'pluralism' this diverse-but-coherent order represents and whether it actually provides the diverse forms of pluralism represented in the literature with any real point of contact.

\section{Pluralism in a plurality of guises}

Bernstein (1987:524) draws attention to the fact that Kuhn (incommensurability of paradigms), Wittgenstein (language games and forms of life) and Derrida (inescapable plurality of languages) are frequently cited to support some version of 'wild pluralism'. He opposes such interpretations and argues that all these forms of pluralism are much closer to what he has characterized as the 'pragmatic understanding of pluralism' in the tradition of Dewey who was committed to the democratic way of life in which communication, dialogue or critical encounter was always a real possibility which required "... passionate practical commitment to be realized" (Bernstein, 1987:511). Watson (1990:355) does not regard Dewey as a pluralist since "... his account of philosophies of knowledge makes all but his own only partial ...". If he were to be a pluralist, Watson argues, 
M.E. Botha

Dewey would have to recognize that it is not he alone who provides an account of the whole, whilst others only have parts, but that both Dewey and those who differ from his philosophy give an account of the whole but differ in the aspect of it which is taken as primary. "Different philosophies would then be seen to be the result of the selection of differing starting points or principles by the mind" (Watson, 1990:356). This type of pluralism Watson calls archic pluralism, i.e. a pluralism which has its source in first principles. Watson (1990:356) also distinguishes three other grand types of pluralism on the basis of their sources: perspectival pluralisn that results from differences in the context and the perspective of the knower; pluralism of hypotheses that results from different hypotheses about reality; methodological pluralism that results from different formulations of a truth that transcends them all. Watson applies these diverse approaches to the interpretation of texts of various kinds. The obvious point of entry to the problem of pluralism in general in Reformational philosophy is the recognition of the modal diversity which not only represents the diversity of ways in which reality exists, but also the possible horizons of experience of reality and scientific access to reality As such these modal structures condition the existence of reality and human experience and knowledge of reality and can accommodate all four grand types of pluralism distinguished by Watson. Yet, Watson's typology departs from a basic assumption that in no way does the recognition of plurality give legitimacy to the unwarranted privileging of one's own position. Both he and James E. Ford (1990:337) would call such a position "dogmatism". Perhaps this is exactly the point where Reformational philosophy provides a different emphasis. Despite Dooyeweerd's protestations to the contrary he develops his account of the Christian philosophical framework as a true philosophical rendering of the Biblical groundmotive of creation, fall and redemption in Jesus Christ - one able to situate or explain the derailments of most others.

One of the fundamental insights of the Reformational tradition has been the emphasis on the development of a Biblically based Christian world view and a Christian philosophical framework which would provide the unifying perspective within which to situate a diversity of theories. There is no doubt about the necessity of such a project, but the academic climate of post-modernism is most certainly not conducive to the imposition of such a total view within the setting of the modern academy. This state of affairs is exacerbated when students are drawn from multicultural and multiconfessional backgrounds. The Christian university is the nodal point 
Does Reformational philosophy have an answer to the many guises of pluralism?

where these crucial issues meet. If one argues that an adequate understanding of structural pluralism is a prerequisite for the positioning of the Christian university in society then an adequate understanding of the implications of confessional pluralism and perspectivalism is a prerequisite for its internal academic calling to Christian scholarship.

There is another facet of pluralism, which is intriguing, when dealt with against the valuable distinction between structure and direction so basic to Reformational philosophy. This fact pertains to the intricate blend of structural and confessional pluralism present in the issue of the plurality of theories with which most scientific disciplines deal within the post-modern university. Even though a university may find its niche within society with the maintenance of all the norms pertaining to structural pluralism and even if its confessional status is recognized and acknowledged by all and sundry and formulated in a mission statement, vision statement and academic creed, the Achilles heel of the Christian university is its attitude towards and critical accommodation of theoretical pluralism in its teaching and research. Both multiculturalism and theoretical pluralism raise questions concerning the 'larger picture' or total view within which such a plurality can be situated and evaluated. This is an issue that requires closer attention. In both cases the relationship of the universal to the particular is at stake. Here we shall primarily deal with theory pluralism.

\section{Theory pluralism}

Post-modernist theory pluralism with its view that there are universally valid, but culturally local sciences, raises the question whether it is possible to identify some common denominator in terms of which issues like incommensurability, relativism, complementarity and contradiction of theories could be judged and evaluated. In post-modernism scepticism has replaced the search for the elusive universal common denominator, a search which has been given up in both instances, because essentialism and foundationalism have been found wanting and unable to provide the required universal support for modernity's notion of truth. Basic to this state of affairs is post-modemism's privileging of the shattering of the subject with its concomitant inevitable splintering of identity; a process to which Feminism and Post-Colonialism also contributed a thorough scepticism about a 'self' that is personal and homogeneous. In this regard John Forrester (1994) says that to think one can recover the holistic understanding of self is an anachronism. And yet, it is exactly such a 
plurality transcending self which is at the 'heart' and the core of Dooyeweerd's Reformational philosophy, both in its transcendental critique of theoretical thought and its discussion of foundational issues in his theory of societal institutions. Furthermore, this plurality transcending 'self' is the focal point of God's central religious law which conditions the diversity of subjects bound by the law.

Theoretical pluralism can be understood in various senses: It can be understood as complementarity of theories, as for example in Bohr's view of the complementarity of wave and particle theories of light. On the other hand, a plurality of theories can also be mutually exclusive or even contradictory. In both cases a more encompassing picture with an implicit understanding (acceptance or rejection) of order is presupposed - an understanding that provides the basic contours functioning as criteria for determining complementarity or contradiction. In the Reformational tradition the notion of the creational order has been a central point of departure - both for the understanding of the diversity of societal structures and their interrelationships - and also for the understanding of the process of theoretical concept formation present within the diversity of scientific disciplines. It is exactly such a notion of universality and stable order that is being contested by recent developments in philosophy of science.

\section{Changing order ${ }^{7}$ or changing concepts and stable order $^{8}$ ?}

Recent developments in philosophy of science have put a strong emphasis on the social or conventional construction of reality as common denominator between theories and positions. Such a pluralism of worlds is seen as a socially constructed phenomenon and the diversity of perspectives or world views which it represents are seen to be reconciled or transcended through social processes such as the conversation of mankind, solidarity and communication. This theme cannot be developed extensively in this article. What is of interest here is the central role of the social construction of reality as it manifests itself in the construction of scientific concepts.

\footnotetext{
7 From the title of H.M. Collins' book (1985).

8 From the title of Hesse's review of Collins' book (1985).
} 
Does Reformational philosophy have an answer to the many guises of pluralism?

In scientific theorizing it is the preoccupation with scientific change and the obvious instability of scientific concepts that has brought about renewed interest in the relationship of stability and order on the one hand and changing perceptions and concepts on the other (cf. Collins, 1985; Nersessian, 1984; Nersessian, 1989). Central to this relationship is the solution of the problem of induction and the understanding of order defended by a school or tradition. In each one of the recent 'turns' (Botha, 1994) in philosophy of science, the quest for order and the perennial search for the elusive 'universal' takes on a different shape, yet in all cases this quest is superimposed on the subject-object divide of the Cartesian legacy (Bernstein, 1983:115).

Reflection on the role of language and language formation in science crops up in most philosophical schools of thought involved in giving an account of the nature and structure of science. This has been the case in the central role of formalized and axiomatized language in logical positivism, but also in most philosophical trends that have followed Wittgenstein in some or other way. Central to most of these projects is the concern for a satisfactory account of how changing languages and displaced concepts can give account of the order perceived in and experienced by all in the same common reality. It is the phenomenon of scientific change amidst the uniformities so characteristic of the world, which continue to intrigue philosophers, philosophers of science and of language. During the course of the sixties the preoccupation with language so characteristic of the linguistic turn' has a concomitant 'turn' to the history of consecutive language games, forms of life and/or scientific paradigms, the so-called historicistic turn (cf. Kisiel, 1974; Shapere, 1966) represented by Hanson, Toulmin, Polanyi, Kuhn, Feyerabend et al. The well-known discussion between Kuhn and Boyd (1980) about the 'joints of nature' exemplifies the way in which especially Kuhn resolved the basic problem concerning the underlying stability and order which makes science possible. Kuhn is not willing to concede the ontological claim entailed by Boyd's position that scientific theories approximate one real world by the accommodation of language to the existing natural kinds in the world (Boyd, 1980:407). On the contrary. Kuhn $(1980: 418,419)$ says:

The view towards which I grope would also be Kantian but without 'things in themselves' and with categories of the mind which could change with time as

9 Cf. the title of Rorty's book (1967). 
M.E. Botha

the accommodation of language and experience proceeded. A view of that

sort need not, ... make the world less real

The historicist emphasis leads to a recognition of and sociological emphasis on the role of the scientific community as initiator and sanctor of the legitimacy of scientific knowledge and language - the sociological turn (Brown, 1984:3-40) with its variations of inter alia conventionalism and constructivism. The historical and sociological 'turns' could be subsumed under the well-known typology of Suppes' (1974:125-27) Weltanschauungsanalyses.

The Strong Programme of Sociology of Knowledge of the Edinburgh School on the other hand, argues that sociology does not only always step in when there is a deviance from the norm of rationality, but that social causes are always present and are determining factors in the production of knowledge. The sociologists refuse to presuppose that scientific beliefs, if compared to beliefs within other human communities or 'tribes', have any special relation to reason, truth or reality. This position which argues that 'epistemic factors are actually social factors', exemplified by Bloor, is qualified as "extreme externalism" by Niiniluoto (1991:139).

Harry Collins' (1985) constructivism or so-called Empirical Programme of Relativism could be regarded as an extreme example of this position. Collins (1985:148) claims: "It is not the regularity of the world that imposes itself on our senses but the regularity of our institutionalized beliefs that imposes itself on the world ... The locus of order is society."

He argues that the natural world has a small or nonexistent role in the construction of scientific knowledge, but concludes that because of the fact that there are groups, societies and cultures, therefore there must be large scale uniformities of perception and meaning (Collins, 1985:5). He wants to develop his EPR as a sociological solution to the problem of induction (Collins, 1985:6).

Collins' position is a Wittgensteinian one in which he anchors rules in language games and language games in social forms of life and ultimately concludes that habitual perceptions are wholly a matter of convention. Collins' thesis is that scientific consensus is in principle indistinguishable from any other sort of persuasion of people to believe in a political, ideological or religious system, or even to believe for purposes of their own class or personal or professional advancement. It is interesting that Mary Hesse (1986) who certainly does not have too much sympathy with 
Does Reformational philosophy have an answer to the many guises of pluralism?

the realist position (she often calls herself a 'moderate realist', when accused of being 'anti-realist'), counteracts this position of Collins with an appeal to the regularities of the psycho-social natural world. Hesse (1986:723) says: "There is a perfectly good explanation of why science exhibits order, namely that it reflects something of the order of the natural world."

In her exposition of the family resemblances and the way in which the recognition and learning of these resemblances takes place she appeals to notions such as "the same experience...", "shared assumptions", "the same physiology", "the same cultural expectations", "irreducible perceptions" that are a function of "our physiology and its commerce with the world" (Hesse, 1985/6:39).

Elsewhere (1988:113) she talks about the "... objective order in the psycho-social-natural world in which we all live (which) is more various and multifaceted than our culture recognizes - more various, but not infinitely various so that any old classification will do for any given social purposes".

In spite of her recognition of these "objective realities" to which language is related she opts for a 'moderate' realist position. Her motivation is clearly the fact that our knowledge of these objective realities is limited, seldom definitive and always open to correction. By and large this is an assumption usually shared by anti-realist thinkers, yet it would be possible to subscribe to this same fact and still be sympathetic to a realist position. McMullin (1984:35) e.g., maintains such a position. She settles for a weaker form of realism (some would argue, for anti-realism) when she says that meanings of predicates in scientific language grow in dynamic interaction with culture and experience; terms do not correspond to universals, Hesse claims. She contends that the threat posed by various forms of relativism following the work of Kuhn and Feyerabend, has led to the undermining of the belief in the reality of laws of nature and their corresponding universals. She (Hesse, 1984:6) says:

\footnotetext{
Radical revolutions of theoretical language call into question the possibility of reaching or even converging upon the ideal theory-language with its 'correct' classification of universals and hence laws, and if there is no convergence, may this not be because there are no ideal natural types?
}

Elsewhere she does acknowledge the fact that the social habits acquired by scientists do reflect the order in the world. She (Hesse, 1988) argues for a socialized epistemology with a reconciliation of various philosophical 
M.E. Botha

positions, but is not willing to agree with Collins that all inductive regularities are purely conventional.

Dooyeweerd's emphasis on the idea of law order, fundamental to both ontological and theoretical diversity, provides a significant avenue to understand the problems posed by the 'turns' in the philosophy of science, with their relativistic consequences referred to above. His recognition of the conditioning and structuring character of God's law for creation and the modal diversity of reality provides fertile avenues of access to understand why the consecutive discovery of new factors operative in theorizing is possible and tempts schools of thought to localize the law or order in some aspect of reality itself albeit the logical, the historical or the social. Succumbing to this temptation inevitably leads to misguided and distorted views of plurality because it confuses perspectives with reified notions of plurality and negates the Reformational philosophical notion of the fullness of meaning and the coherence of diversity which relativizes any hypostasized notion of plurality. It is exactly this process of hypostatisation, which is both the cause and the result of wild pluralism - hypostatisation that can be counteracted through the recognition of the relationship of all forms of diversity to a plurality transcending point of reference.

This state of post-modern culture confronts us with the intriguing problem of cultural pluralism and the challenges it poses to the Christian university. Griffioen (1994) formulates this challenge succinctly:

The challenge a Christian university faces ... is to serve as a public forum in a multicultural society. Being at the crossroads of structural pluralities (as university) and directional diversity (as a Christian institution) it can be expected to be sensitive to all the pluralities at stake.

In the following section some aspects of this challenge will briefly be discussed.

\section{The Christian university and multiculturalism}

Multiculturalism obviously is a multifaceted phenomenon. In a far stronger sense than in most other societal phenomena one discerns the entanglement of elements of structural and confessional pluralism in this phenomenon. There are strong elements of what has traditionally been called ethnicity or cultures in the social anthropological sense of the word (Young, 1976, ch. 2). Here one thinks of the ethnic areas and suburbs in 
Does Reformational philosophy have an answer to the many guises of pluralism?

many North American metropolitan areas. There are also strong elements related to lifestyle and morals, such as the Californian gay lifestyle. In post-modernism the term is often used to designate the right of groups to their own understanding and interpretation of life and values and the equality and relativity of these lifestyles and values. When the phenomenon is dealt with in a political context it calls forth the issue of rights of groups coupled with the concomitant notion of universal human rights. I agree with Griffioen (1994) that human rights ought to be seen primarily as a juridical or legal notion, especially when it crops up within the modern political system. There is another dimension which ought to be recognized in this respect. It is the kernel of truth at the core of both universalism and particularism. It could be illustrated by the dilemma posed by the development of (Western) universities in Third World cultural contexts.

The introduction of the notion of a university into a less developed culture (I recognize the value laden nature of this statement) inevitably leads to a destruction of the indigenous culture and a replacement with typically Western standards and values. An opponent of such a position could argue from the perspective of multiculturalism that such an imposition is not morally justified. The critical question African universities, however, have to deal with is how to reconcile the diverse value systems within a multicultural setting with the traditional and age-old universal values epitomized by the university. Perhaps the situation of a Christian university within a multicultural society in transition, as is the case in South Africa, could be the best possible case study in this respect. A university per definition embodies universal values and the search for some sort of 'universal truth'. But local, cultural, regional and national issues force this universal ideal to come to terms with the local and the particular. Questions such as the following need to be dealt with:

* How does one adapt the typical Western concept of the university to the needs of developing countries and people?

* Is there a cultural form or guise in which the university can come closest to fulfilling its specific cultural and educational task?

* Is it possible to meet the needs of Third World peoples without inevitably denaturing the structure of the university?

These are all important issues and ones that require close attention of the international Christian scholarly community. Moreover, they are issues with which South African Christians cannot deal alone. As relevant and 
M.E. Botha

crucial as the critical input was from Christian scholars during the apartheid era, as crucial and decisive will be the contribution of Christian scholars who help think through how the complex issues at stake here, can be redemptively resolved. Interestingly enough, exactly the modernistic and universalistic notion of rationality which has always provided a steadfast anchor for discussions of this kind, has thoroughly been eroded and discredited. Moreover, the experience of many South African universities has been that the type of academic knowledge provided within the setting of the university has proved to be far removed from the typically contextual needs and requirements of developing cultures.

\section{Plurality and diversity within the context of a global and total view}

Both theoretical pluralism and multiculturalism raise the question whether there is some universal common denominator which transcends or unifies the plurality or diversity of theoretical perspectives on science or cultures present within a society. Dooyeweerd's Christian philosophy departed from this basic question concerning a common denominator of and for reality. In this process he came to the conclusion that a Scripturally informed answer to three basic questions is a prerequisite for the development of a Christian view of society and a responsible theoretical account of the unity and coherence in diversity of societal structures. (The three basic questions, according to Dooyeweerd, concern the issues of origin, unity, coherence and diversity of societal structures.) Fundamental to the so-called sociological ground idea is Dooyeweerd's (1957:169) view that all societal structures of individuality find their radical unity and totality of meaning " $\ldots$ beyond cosmic time in the central religious community of mankind"."

I shall not deal with the discrepancies which are apparent when one formally compares the triad of transcendental ideas in Dooyeweerd's development of the modal and the sociological groundidea respectively, except to point to the fact that the central religious community of mankind functions both as a transcendental apriori for the existence of the diversity

10 The ambivalent ways in which Dooyeweerd formulates the relationship between the heart and central religious community of mankind has been dealt with extensively by Botha (1971) and Strauss (1972). 
Does Reformational philosophy have an answer to the many guises of pluralism?

of structures and is also a condition for a correct theoretical understanding of societal sphere sovereignty.

A crucial issue in this respect is the question whether recognition of and obedience to structural principles for societal structures can be accomplished without the fundamental religious commitment to Christ. The formulation of the principle of structural pluralism often creates the impression that it is possible to recognize such structural plurality as a neutral or common (?) state of affairs, without it being accompanied by a communal commitment to the basic tenets of the Christian faith. Commitment to the Christian faith is a prerequisite as the Christian faith is recognized as being able to make both the understanding of the relationships between structures possible and to provide protection against the temptations of relativism and universalism. Given, Dooyeweerd's formulation of the relationship between Jesus Christ's redemptive work in creation and recreation makes it possible to argue that even those who are not 'in Christ', but are obedient to the structural norms for a given situation, can share in the blessings of what has traditionally been called 'common grace'. I, however, do think those who argue that one cannot divorce the obedience to structures and societal norms from the fundamental ultimate commitment to the giver of these norms, the Sovereign God, have a very strong point. It is exactly at this point where the tension between a common denominator and the directional antithesis surfaces - a tension that cannot be easily resolved.

\section{Bibliography}

BERNSTEIN, RICHARD J. 1983. Beyond Objectivism and Relativism. Science, Hermeneutics and Praxis. Philadelphia : University of Pennsylvania Press.

BERNSTEIN, RICHARD J. 1987. The Varieties of Pluralism. American Journal of Education, 95(4):509-525.

BOTHA, M. ELAINE. 1971. Sosio-kulturele metavrae. Amsterdam : Buijten en Schipperheijn.

BOTHA, M. ELAINE. 1994. Understanding Our Age. Philosophy at the Turning Point of the 'Turns'? The Endless Search for the Elusive Universal. (In Botha, E., Duvenhage, P. et al., reds.. Wysgerige perspektiewe op die 20ste eeu. Bloemfontein : Tekskor. p. 16-31.)

BOYD, RICHARD. 1980. Metaphor and Theory Change: What is "Metaphor" a metaphor for? (In Ortony, A., ed. Metaphor and Thought. Cambridge : Cambridge University Press. p. 356-408.) 
M.E. Botha

BROWN, J.R., ed. 1984. Scientific Rationality: The Sociological Turn. Dordrecht : Reidel.

COLLINS, H.M. 1985. Changing Order. Replication and Induction in Scientific Practice. Chicago : University of Chicago Press.

DOOYEWEERD, H. 1941. De transcendentale kritiek van het wijsgerig denken en de grondslagen van de wijsgerige denkgemeenschap van het Avondland. Philosophia Reformata, 6:1-20.

DOOYEWEERD, H. 1957. A New Critique of Theoretical Thought, vol. III. Amsterdam : Paris.

FORD, JAMES E. 1990. Systematic Pluralism: Introduction to an Issue. The Monist, 73:336-349, July.

FORRESTER, J. 1994. Paper read at the Conference on "Knowledge, Power and the Public Good" organized by the Centre for Scientific Development of the South African Human Sciences Research Council, July 1994. Pretoria.

GARVER, EUGENE. 1990. Why Pluralism Now? The Monist, 73:388-410, July.

GRIFFIOEN, SANDER. 1994. The Relevance of Dooyeweerd's Theory of Social Institutions. Paper read at the Fifth International Symposium of the Association for Calvinist Philosophy, August 22 - 26, 1994, Hoeven, The Netherlands.

HESSE, M.B. 1972. The Explanatory Function of Metaphor. (In Bar-Hillel, Yehoshua, ed. Proceedings of the 1964 International Congress for Logic, Methodology and Philosophy of Science. Amsterdam : North Holland. p. 249-259.)

HESSE, M.B. 1984. Texts without Types and Lumps without Laws. Response to a paper by R. Rorty. "Texts and Lumps". Page references to unpublished article. Published in 1985 New Literary History, 17 (1985/6) i 3148.

HESSE, M.B. 1986. Changing Concepts and Stable Order. Review of H.M. Collins, 1985. Social Studies of Science, 16:714-726.

HESSE, M.B. 1988. Socializing Epistemology. (In McMullin, Ernan. Construction and Constraint. The Shaping of Scientific Rationality. Notre Dame : University of Notre Dame Press. p. 97-122.)

KISIEL, THEODORE. 1974. New Philosophies of Science in the USA. Zeitschrift fur Allgemeine Wissenschaftstheorie, 5(1):138-191.

KUHN, T.S. 1980. Metaphor in Science. (In Ortony, A., ed. Metaphor and Thought. Cambridge : Cambridge University Press. p. 409-419.)

MCCARTHY, R., OPPEWAL, D., PETERSON, W. \& SPYKMAN, G. 1981. Society, State \& Schools. A Case for Structural and Confessional Pluralism. Eerdmans : Grand Rapids. 
Does Reformational philosophy have an answer to the many guises of pluralism?

McINTIRE, C.T. 1985. Dooyeweerd's Philosophy of History. (In McIntire, C.T., ed. The Legacy of Herman Dooyeweerd. Lanham : University Press of America. p. 81-118.)

McMULLIN, E. 1984. The Rational and the Social in the History of Science. (In Brown, J.R., ed. Scientific Rationality. The Sociological Turn. Dordrecht : Reidel. p. 127-164.)

MITCHELL, W.J.T. 1986. Pluralism as Dogmatism. Critical Inquiry, 12:494502 , Spring.

MOUW, RICHARD J. \& GRIFFIOEN, S. 1993. Pluralisms and Horizons. An Essay in Christian Public Philosophy. Grand Rapids : Eerdmans.

NERSESSIAN, NANCY J. 1984. Aether/or: The Creation of Scientific Concepts. Studies in the History and Philosophy of Science, 15:(3):175-212.

NERSESSIAN, NANCY J. 1989. Conceptual Change in Science and Science Education. Synthese, 80:163-183.

NIINILUOTO, I. 1991. Realism, Relativism and Constructivism. Synthese, 89:135-162.

PLANTINGA, THEODORE. 1991. Christian Philosophy within Biblical Bounds. Neerlandia : Inheritance Publications.

RORTY, J.R., ed. 1967. The Linguistic Turn, Recent Essays in Philosophical Method. Chicago : University of Chicago Press.

SHAPERE, D. 1966. Meaning and Scientific Change. (In Colodny, Robert G., ed. Mind and Cosmos. Essays in Contemporary Science and Philosophy. Pittsburgh : University of Pittsburgh Press. p. 41-85.)

STRAUSS, D.F.M. 1972. The Central Religious Community of Mankind. Philosophia Reformata, 37:58-67.

SUPPES, FREDERICK. 1974. The Structure of Scientific Theories. Urbana : University of Illinois Press.

TOULMIN, S. 1971. Rediscovering History. Encounter, 36(1):53-64, January.

VAN RIESSEN, H. 1970. Wijsbegeerte. Kok : Kampen.

WATSON, WALTER. 1990. Types of Pluralism. The Monist, 73:350-366, July.

WOLTERSTORFF, N. 1984. Reason within the Bounds of Religion. Grand Rapids : Eerdmans.

YOUNG, CRAWFORD. 1976. The Politics of Cultural Pluralism. Madison : University of Wisconsin Press. 